\title{
El Concepto de Patria como Integración Cósmica en \\ La Guerra Gaucha
}

\author{
I-EL GAUCHO LUGONIANO
}

$\mathrm{L}$ EOPOLDO LUGones ha presentado, en La Guerra Guucha, el eslabón que existió entre la cultura hispánica que se volcó sobre suelo ameriçano con anterioridad a la época de la emancipación y la resultante criolla y argentina que existe en nuestros días. Este eslabón fue el gaucho, tipo racial de cultura intermediaria, necesario históricamente para poder determinar el proceso por el cual un punto geográfico, un momento histórico, un grupo de gente y una forma de vida pueden sintetizarse en un concepto propio de nacionalidad.

El gaucho lugoniano define, mejor que ningún otro, su objetivo histórico-social. No es, sin embargo, el mejor exponente de la cultura gaucha en la literatura americana. No es esto lo que más importa en el contenido de la obra. La raza que Lugones describió en La Guerra Gaucha no intenta explicar y defender su propia situación en el mundo, pero sí actuar sobre éste, aniquilándose en el proceso y dejando a su paso la huella de su personalidad.

El gaucho que Lugones incorpora a nuestra literatura ha roto sus lazos con la tradición española y ha emergido personal, independiente, lleno de vida, hijo indiscutido de la tierra americana. La integración del gaucho con esta realidad americana, en $L a$ Guerra Gaucba, se realiza en momentos en que dicha realidad se encuentra en un proceso formativo, en vías de definirse precisamente en la época que precede a la fecha de la emancipación. El gaucho, cntonces, aparece como un vínculo indispensable en el proceso histórico, que habrá de culminar en la fijación de un concepto integral de "patria". 


\section{2-LOS TRES ELEMENTOS DE LA INTEGRACIÓN CóSMICA}

Las veintidós narraciones que forman $L_{a}$ Guerra Gaucha constituyen una epopeya en prosa de las luchas por la independencia argentina, en las que el gaucho tuvo un papel de fundamental importancia a principios del siglo pasado. Las narraciones son independientes entre sí. Sin embargo, en todas ellas se exalta la figura del gaucho, y se imprime a sus acciones una intensidad y grandeza de proporciones épicas.

Los personajes de dichas narraciones se caracterizan por sus cualidades y virtudes. Son ejemplos de una cultura en la que la integridad física y moral es el elemento sobresaliente. Esta posición ideal que ocupan dentro del mundo de la novela determina que ni aún los elementos negativos de su realidad social, incluyendo crimenes, derrotas militares o prácticas injustas, puedan destruir la impresión que el lector tiene de su personalidad heroica. De este modo, el pueblo mismo en que todos estos elementos se combinan--su cultura, tradiciones y anhelos-actúa como protagonista de la obra. El ser humano es sólo un elemento más en su composición. El hombre es un ser incompleto, insuficiente por sí mismo, que sólo puede determinar su naturaleza y adquirir importancia al integrarse en una unidad cósmica.

En La Guerra Gaucha la integración cósmica del individuo se logra por la ligazón intima de tres elementos básicos. Son éstos el hombre, ser limitado e incapacitado; la Naturaleza, que complementa y define al ser humano a lo largo de la obra; y una energía metafísica que actúa como una voluntad superior a la que los demás elementos de la obra están sujetos. Estudiando en detalle la obra encontramos los siguientes lazos de correspondencia entre dichos elementos:

\section{a) Relación de bombre y Naturaleza.}

Dentro del mundo de La Guerra Gaucha el elemento humano y la Naturaleza se influyen mutuamente, se dan nuevos significados, y aumentan sus posibilidades dramáticas al fundirse uno en la otra. Los contrastes y similitudes que presentan realzan algunas de sus características. Ambos elementos se dan, sin embargo, en unidad armónica. Ya desde la primera narración, denominada "Estreno", encontramos un ejemplo de este proceso. La profundidad y el misterio que rodean a los montoneros, las cumbres, el cielo, el aire mismo que respiran, disuelven, en su inmensidad, la voz humana; ésta es sólo sonido, perdido súbitamente en el silencio de la noche, y el hombre que habla, al perder su identidad individual, se convierte en 
parte de la misma. El conjunto de hombres forma una unidad indivisible dentro de la realidad natural que le rodea. Los hombres que allí, amontonados, sufren el frío de la noche, son cuerpos sin rostros y sin nombres; sólo forman parte del paisaje, del silencio, del conjunto integrado de las cosas. I En "Carga" encontramos esta magnífica descripción, en que es obvio el paralelo entre la actividad humana y las fuerzas de la Naturaleza:

Grandes relámpagos lavaban el horizonte. Un trueno reventó con claridad insólita su rotundo borbollón de erres y eles. Abajo, como si lo repercutiera, farfulló un iracundo palabreo. Los jefes altercaban. El hombre de por la tarde divergía, pringando de juramentos su discurso. Replicaban los otros ... Tronó por segunda vez, y el nasardo del trueno completó la frase barbotando una blasfemia (384).

En la narración denominada "A Muerte", el viento actúa como agente unitivo entre Naturaleza y hombre. Dice el narrador:

Soplos de viento mezclaban sus cabelleras removiendo en profunda palpitación la masa del bosque (39I).

En la misma narración podemos encontrar este otro ejemplo del mismo tipo de interrelación:

El paisaje se contagió con el padecimiento del hombre que agonizaba; respiró su congoja empañando las nubes (387).

En "Despedida" el procedimiento es semejante, y el efecto de completa integración se realiza una vez más:

Y mientras a la luz del cielo grisáceo donde lucía una desamparada estrella... el viejo, apoyada la mejilla en sus brazos puestos sobre la cruz de la bestia, se abismaba en sus recuerdos. La melancolía crepuscular, como una hebra de humo, lentamente ascendia en su alma; y sus ideas adormecianse... Y a medida que el hombre aglomeraba pensamientos las lomas vecinas llenábanse de noche (366).

1 Leopoldo Lugones, "La Guerra Gaucha", en Obras en prosa de Leopoldo Lugones (Madrid: M. Aguilar, editor, 1962), p. 300. [Todas las citas siguientes son tomadas de esta edición. Indicamos la página correspondiente al final de la cita]. 
b) Relacion entre lo sobrenatural y el mindo concreto.

En el mundo heroico de La Guerra Gaucha lo sobrenatural está por encima de todos los demás elementos para dirigirlos y determinarlos. El destino de los gauchos o de los godos está ligado en forma ineludible a una decisión divina. En consecuencia, toda una maquinaria derivada de estas fuerzas es puesta en acción para favorecer y defender a los héroes con truenos, rayos o terremotos. Por ejemplo, la vieja Getrudis de la narración "Castigo" es capaz de producir hechizos contra la gente que odia, segura de tener a Dios mismo de su lado cuando se trata de castigar a los godos. Un instante después de que su maldición perfora el silencio de la calle, llega desde lo alto la contestación en la forma de un rayo que mata al enemigo de los gauchos. Dice el narrador:

El rayo de Dios y de la Patria, realizando el conjuro, castigaba la impiedad del enemigo y marchaba a guisa de sable predecesor con sus batallones de nubes y su artillería de aerolitos... (377)

Y para que no haya lugar a dudas acerca del carácter sobrenatural de la intervención, encontramos aún más detalles sorprendentes:

... El cadáver se pudrió aquella misma noche con tal premura, que lo enterraron al amanecer sin despojarlo siquiera de sus adornos, sobre los cuales supuraba con hedor funesto la ponzoña de la maldición $(378)$.

En el episodio denominado "Baile", la intervención de elementos sobrenaturales en momentos en que parece que los godos habrán de disfrutar de una victoria total, determina que el resultado de la refriega sea la muerte heroica para el gaucho, y para su enemigo el recuerdo permanente de su cobardía. En "Milagro", el elemento sobrenatural es aún más evidente. La imagen de la virgen, presente en momentos en que se castiga a la anciana criolla por haber ofendido al rey godo, palidece, "lacerada por milagrosa transficción" (402). Y no nos sorprende que, en el episodio "Al rastro", los godos, que intentan escaparse, se encuentren con que su última salida aparezca bloqueada por una pirca. Se detienen, entonces, porque comprenden que "semejante colaboración de azares, sobrentendía conjuraciones misteriosas" (452).

$\mathrm{La}$ integración de los tres elementos básicos de la obra: lo sobrenatural, lo humano y la Naturaleza circundante, of rece la posibilidad de 
una realidad cósmica indivisible; y si el hombre que llegamos a conocer en las páginas del libro parece disolverse, diluirse, desaparecer o integrarse en el cosmos, el efecto es una unificación o determinación del mismo: la impresión de que éste se ha perfeccionado al lograr un equilibrio entre los diferentes elementos.

En esta unidad cósmica las cualidades espirituales propias del ser humano, como el valor, el amor, el odio o la esperanza, han de conservarse indestructibles aún después de que la naturaleza física del individuo haya perdido sus funciones vitales. La integración de las cualidades esenciales del individuo con el medio ambiente, y a través de éste con una realidad cósmica, sólo se puede realizar cuando dichas cualidades se liberan de las limitaciones que le son impuestas en un plano individual por lo puramente físico, a través de una acción gloriosa o muerte heroica. Tomemos, por ejemplo, la narración "Estreno". En ella, aun cuando el soldado que baja por el precipicio muere, el lector conserva en su memoria la imagen de su actitud heroica, del valor, del amor por la bandera y por la patria que aquél demostró en todo momento. La mujer quemada y violada de la narración "Baile", no pierde en la lucha sus cualidades esenciales, y al iniciar su trágico y horrible peregrinaje con el niño muerto en sus brazos, se transforma en la Madre ideal, la Mujer ideal, y la personificación de la resignación y la perseverancia.

\section{3-Determinación del Concepto de Patria}

Las cualidades espirituales del individuo cobran fundamental importancia dentro de la obra debido, en gran parte, a que el elemento humano cumple a menudo una función simbólica. Como consecuencia de esto, las emociones y sentimientos de los personajes son más importantes que las acciones que los motivan.

Encontramos en diversas oportunidades que el diluirse de lo puramente objetivo y la perpetuación de lo espiritual en un plano cósmico llega a tal que el individuo se convierte en monumento permanente de sus propias cualidades. Por ejemplo, del niño héroe que muere en el episodio denominado "Sorpresa", el narrador nos dice: "La muerte heroica lo acuñaba en su bronce" (3I8). En "Artillería", la bella y orgullosa mulata se convierte, en vida, en imagen generosa de patriotismo y lealtad. La descripción de su estatuaria figura reza de este modo:

... La beldad tutelar aventajaba con todo el busto las cabezas, mol- 
deado su seno en turgencia de proa generosa bajo el raso natanja que la tarde oxidaba con su reflejo, hasta convertir en una estatua de metal flavo su hermosura dramatizada de fatalidad (427).

Los personajes mismos parecen desdeñar lo puramente mortal, o físico. En la narración "Chasque", el gaucho se convierte en humano meteoro que siembra la muerte por doquier en campo enemigo, y que sólo la completa destrucción física logra contener. $\mathrm{Ni}$ aún los godos, cuyos compañeros han sido asesinados por el patriota, logran disimular su admiración y su asombro ante la orgullosa temeridad del mismo. $\mathrm{Y}$, sin embargo, tampoco en este caso es la acción lo que más inquietud nos produce y lo que al final habremos de recordar. Es la actitud del herido, quien, cuando el jefe enemigo le pregunta su concepto de patria, tiende un brazo hacia el horizonte y abarca con su mirada los ríos, los campos, la noche. Su gesto da significado, no sólo a la acción heroica que le llevó a una muerte prematura, sino a toda una vida pasada. Cuando el individuo muere, la patria se convierte en depositaria de las cualidades y los actos más bellos y esenciales del héroe. El mundo de La Guerra Gaucba se integra de este modo, y no es ya sólo ríos, montañas, valles y crepúsculos, sino vientos y soles vivientes, que sufren dentro de sí la muerte de sus hijos. La integración que observamos tiene una cualidad especial, algo que le da posibilidades literarias, y un objetivo artístico, dramático, propio. Todos los elementos se inclinan, se dirigen a una definición integral del concepto de patria. Patria como una combinación de elementos esenciales: humanos, físicos e ideales.

Aun cuando $L_{a}$ Guerra Gaucha se interesa por lo esencialmente patriótico, por el ansia de libertad más que por la lucha que logró finalmente conseguirla; por el amor que la engendró más que por los seres que debieron ser sacrificados en su holocaustó, es indudable que en sus páginas también se trata de determinar una realidad fisica que pertenece a un punto geográfico y a un momento histórico especiales. No se habla en esta obra de un grupo cualquiera de personas en un punto del globo elegido al azar. La Guerra Gaucba ensalza las cualidades espirituales con que la cultura gaucha, de acuerdo con las teorias que sugiere la narración, ha impregnado el suelo argentino; determina actitudes, normas, modos de vida, filosofías y creencias pertenecientes a la cultura gaucha según se integraron para definir un concepto individual de nacionalidad. La personalidad del gaucho se ve a través de descripciones, sobre todo de grupos, los cuales parecen cumplir una función ejemplificadora. El gaucho 
aparece como un individualista, acostumbrado a bastarse a sí mismo; silencioso como el campo, es corto de palabras al conversar, y en algunas ocasiones habrá de meditar en alta voz. Detesta al extranjero que le somete a una condición servil; por eso, el motivo de su Jucha se basa más en su instinto de libertad que en un principio moral. Es supersticioso y valiente. De la mujer es amo; del caballo y del perro, amigo. Aún los gauchos que aparecen descritos en la obra en forma independiente parecen tipificar algún aspecto de la raza a la que pertenecen, sin cobrar gran valor como personajes independientes dentro de la obra. Por ejemplo: conocemos al patriota ciego de la narración "Sorpresa", quien, al morir, deja vibrando en el mismo aire en que vivía las notas graves y sonoras del "Himno Nacional"; o al viejo Florencio del capítulo intitulado "Serenata", que une a su indoblegable voluntad el amor por la música y por la libertad.

La mujer, en el mundo de La Guewa Gaucha, aparece como el elemento simbólico que da significado a los sentimientos patrióticos del gaucho. Es su compañera inseparable, y como tal, habrá de luchar contra la soledad, el enemigo o cualquier obstáculo que se interponga entre ella y el hombre a quien pertenece. En "Chasque", por ejemplo, encontramos a una muchacha que, por amor al gaucho que lucha en las montoneras, habrá de sacrificar todo, hasta su honor, para llegar a él. Sin embargo, la mujer no es sólo la compañera del gaucho, su cocinera en los fogones y un objeto de satisfacción sexual. Ella representa la patria: su tierra y su bandera. La mujer de "Juramento", en la descripción que hace el narrador, aparece de este modo:

Celeste la falda y blanco el corpiño... Airosa se cimbreaba en los lomos del animal que con la vibración de su brío la estremecía como a una flor del agua la corriente (349).

La imagen de la mujer como bandera continúa:

[Su novio, volviéndose hacia ella]... le expresó la fidelidad de esos valientes que a su amparo luchaban, comprometióle la victoria en arras sublimes. Ella la simbolizaría en los combates, con su nombre en los labios morirían, y para demostrárselo mejor, a ella en persona jurarian por bandera (350).

En "Baile" dice el narrador de la mujer: 
Sus entrañas partidas como las de la comarca natal, escondian también volcanes $\left(33^{8}\right)$.

En "Alerta", la anciana guarda, en cambio, como la tierra misma de su patria, el recuerdo y la esperanza de libertad de siglos de sufrimiento y de esclavitud (313).

El espíritu de rebelión, nacido de un profundo deseo de libertad, crea a través de la obra el concepto de patria. Todas las creencias, actitudes y costumbres parecen señalar una propiedad común: la de pertenecer a una Naturaleza y a un modo de vida propios. El espíritu nacional y patriótico se define, en última instancia, por la purificación e integración cósmica del gaucho que sucumbe a una muerte heroica. Un mundo esencial y puro se va definiendo a través de la acción. Es como si ésta transcurriese en un primer plano, mientras la esencia misma de las cosas, pasando a través de ella como por filtro finísimo, bordase en el fondo un mundo singular, auto-suficiente y significativo. En algunas ocasiones, el dualismo entre lo físico y lo espiritual es demasiado obvio para pasar inadvertido. La vieja hechicera de la narración "Castigo", quien parece haber sido la elegida de Dios para anticipar sus actos en el mundo, tiene una apariencia física absolutamente repugnante:

Bajo la harapienta falda estremecíanse con sanguinolenta hinchazón sus piernas que la hidropesía abotagaba; un rebozo apolillado al parecer por larvas de sepulcro cubría sus hombros y su cabeza... Doblada enteramente en dos, sus manos fofas de batracio se aferraban al garrote; y regoldaba más que decía, con un leleo de niño, palabras sueltas caducando en repugnante decrepitud (375).

El personaje con que nos encontramos en la narración "Vado", quien, hacia el final del capítulo demuestra caracterizarse por un patriotismo y una heroicidad de difícil superación, responde a la siguiente descripción:

El imbécil se enderezó, todo flacucho entre sus pingajos, lastimosamente chamorro. Reía y su rostro congelado por la mueca, semejaba un higo en el cual revolvía su mucosa la jeta. Sacudíalo un temblorcillo de congoja, humedeciéndose a la vez sus lagañosos párpados. Hedía como un niño sucio, a costras lácteas y pringue dermal (405).

El cabildante potosino de la narración "Castigo", aun cuando luce en vida 
la riqueza y ornamento de sus bienes materiales, al morir sólo deja un testamento de horror, y el recuerdo de su egoísmo, vanidad y cobardía.

Seria posible definir dos mundos de igual importancia dentro de la obra. Uno de ellos, concreto, fácilmente reconocible, representado por cualquiera de los elementos físicos, sean éstos rayos, árboles, perros o niños. $Y$ otro, un tanto más difícil de abstraer y de definit, que abarca los significados, las ideas, las fuerzas que determinan la acción, y la atmósfera en la que lo más esencial de la personalidad de un hombre o de una raza encuentra una posición de articulación junto a la inmensidad de lo inaccesible y de lo eterno.

La interrelación de estas dos unidades: el mundo físico, mecánico. momentáneo, perecedero, y aquél constituido por los valores y los elementos ideales - que no pueden ser destruidos, y que habrán de persistir como elementos inalterables de la realidad-determina el concepto de patria, esencia misma del mundo que Leopoldo Lugones creó en $L a$ Guerra Gaucha. 
